\title{
Satisfaction With Social Networks: An Examination of Socioemotional Selectivity Theory Across Cohorts
}

\author{
Jennifer E. Lansford, Aurora M. Sherman, and Toni C. Antonucci \\ University of Michigan
}

\begin{abstract}
This study examines L. L. Carstensen's (1993, 1995) socioemotional selectivity theory within and across three cohorts spanning 4 decades. Socioemotional selectivity theory predicts that as individuals age, they narrow their social networks to devote more emotional resuurces to fewer relationships with close friends and family. Data from 3 cohorts of nationally representative samples were analyzed to determine whether respondents' satisfaction with the size of their social networks differed by age, cohort, or both. Results support socioemotional selectivity theory: More older adults than younger adults were satisfied with the current size of their social networks rather than wanting larger networks. These findings are consistent across all cohorts. Results are discussed with respect to social relationships across the life course.
\end{abstract}

This study was designed to examine Carstensen's (1993, 1995) socioemotional selectivity theory, which explains agerelated change in social behavior in terms of emotion conservation and goals for interpersonal interactions. According to socioemotional selectivity theory, across the life span, individuals gradually interact with fewer people as they deliberately withdraw from social contact in peripheral relationships, while maintaining or increasing involvement in relationships with close friends and family. This selective narrowing functions adaptively to maximize gains and minimize risks in social and emotional domains. Before considering this study and outlining socioemotional selectivity theory in more detail, it is useful to review briefly other theories that have been proposed to explain decreased social interaction in later life. The most prominent of these are activity theory (Havighurst, 1961; Havighurst \& Albrecht, 1953; Maddox, 1963, 1965) and disengagement theory (Cumming \& Henry, 1961).

Activity theory (Havighurst, 1961; Havighurst \& Albrecht, 1953; Maddox, 1963, 1965) is based on the premise that older people desire social contact but are impeded from such interactions by social and physical barriers such as mandatory retirement and deaths of loved ones. Because social inactivity is viewed as a problem imposed by factors external to the individual, proponents of activity theory argue that social change is

Jennifer E. Lansford, Aurora M. Sherman, and Toni C. Antonucci, Department of Psychology, University of Michigan. Aurora M. Sherman is now at the School of Medicine, Wake Forest University.

This research was supported by National Institute on Aging Grant P20AG12846. Portions of this research were presented at the 105th Annual Convention of the American Psychological Association, Chicago, Illinois, Angust 1997.

We are very grateful to Elizabeth A. Vandewater and Halimah Hassan for their helpful comments on drafts of this manuscript.

Correspondence concerning this article should be addressed to Jennifer E. Lansford or Toni C. Antonucci at the University of Michigan, Department of Psychology, 525 East University, Ann Arbor, Michigan 48109-1109. Electronic mail may be sent to jlansfor@umich.edu or tca@umich.edu. needed and that public programs should be implemented to address this issue. Empirical findings often do not support activity theory, however. For example, when given opportunities for social contact, older people regularly bypass them, and interventions designed to increase social contacts among older adults have not had long-term effects (Carstensen, 1986; Carstensen \& Erickson, 1986). Furthermore, most older people report being happier with their lives (Herz.og \& Rodgers, 1981) and less lonely (Larson, 1978) than do younger people. Because activity theory argues that mandatory retirement and other societally imposed policies hinder older adults from having as much social contact as they desire, cohort differences may be expected as a result of changes in public policies and resources available to older adults over time. For example, if retirement is imposed on older adults against their will, resulting in decreased social contact with coworkers, one would expect older adults to report being less satisfied with their social networks. On the basis of activity theory, one would conclude that older adults would only be happier with their lives and less lonely when external, societal factors enabled them to have the social contacts they desire.

In contrast to activity theory, disengagement theory (Cumming \& Henry, 1961) posits that decreased social interactions during later life are the normative and adaptive result of a mutual withdrawal of the individual from society, and society from the individual as the aging person prepares for death. The disengagement process is driven by an emotional distancing of the older adult from others. This theory accounts for the results discussed above that are inconsistent with activity theory (i.e., older people bypass opportunities for social interaction and are satisfied with their lives), but is generally not supported by other empirical studies (Carstensen, Gottman, \& Levenson, 1995; Lang \& Carstensen, 1994). Although overall frequency of social interaction does not predict life satisfaction in older adulthood, the quality of social relationships does predict mental and physical health (Antonucci \& Jackson, 1987; Blazer, 1982). In addition, older adults are often more emotionally invested in their relationships than are younger individuals because peripheral relationships with less close network members are no longer maintained (Lang \& Carstensen, 1994). Older people reduce 
their contact selectively such that although they may have fewer interactions with their network members overall than younger people, the number of long-time friends and close family members included in their social networks is about the same (Lang \& Carstensen, 1994).

Like disengagement theory, socioemotional selectivity theory holds that decreased social contact is a function of individual choice rather than imposed against the individual's will. Because decreased social contact is internally driven rather than externally imposed according to both disengagement and socioemotional selectivity theory, neither of these theories would predict cohort differences in satisfaction with social networks and contacts. However, these two theories propose different motivating forces and end results associated with this decrease in social contact. Socioemotional selectivity theory takes the life-course perspective that social interaction is motivated by social needs that are present, but change in salience, across the life span (rather than a process specific to older adulthood as proposed by disengagement theory, namely preparing for death).

More specifically, socioemotional selectivity theory proposes that two social motives-information seeking and emotion regulation - vary in importance across the life span (Carstensen, Gross, \& Fung, 1998). Information seeking is most important in childhood, adolescence, and younger adulthood as the individual learns about the world, how it works, and his or her place in it. Contact with new people helps provide such information. Information seeking as a goal, however, becomes less salient later in life as individuals become increasingly well-versed in information about the world. Emotion regulation, including motives to feel good, establish intimacy, and derive emotional meaning from life, increases in importance during older adulthood when more future-oriented motivations are becoming less salient. When emotion regulation is the primary motivation, familiar or intimate social partners are preferred over novel people because the former are more likely to provide support and engender feelings of emotional gratification. Thus, fewer social contacts are likely to be made in pursuit of emotion-related goals in favor of interactions with a select few close partners (Carstensen et al., 1998).

According to socioemotional selectivity theory, goals for social interactions change in part as a result of changes in individuals' construal of the future (Carstensen, 1995). When individuals perceive their future to be limited, their goals shift to fulfillment of current needs, and emotions become more salient. Long-term goals are more salient when the future is perceived as open-ended. Older age generally corresponds with regarding the future as more limited, but when younger people regard the future as limited because of terminal illness or an impending move to a new geographical location, their goals shift from long-term aspirations to fulfillment of immediate needs (Fredrickson \& Carstensen, 1990). Having a sense that the future is limited is related to preferring to spend time with close friends or family rather than novel social partners (Fredrickson \& Carstensen, 1990).

\section{Empirical Support for Socioemotional Selectivity Theory}

Carstensen and her colleagues (e.g., Carstensen, 1992; Fredrickson \& Carstensen, 1990; Lang \& Carstensen, 1994) have carried out an extensive research program investigating the social lives of older adults. Using a wide range of methods and different samples, they have demonstrated support for socioemotional selectivity theory. A brief outline of selected studies is provided below to offer a perspective on how this study can contribute to the growing body of knowledge regarding this theory.

Fredrickson and Carstensen (1990) conducted two studies that specifically address the question of whether novel or familiar social partners are preferred by younger and older adults. When asked who their most preferred social partners would be, teenagers were most likely and nursing home residents were least likely to include a novel social partner in their list. When asked with whom they would choose to spend time, older respondents chose familiar social partners more frequently than did younger respondents. Results from these studies suggest that older respondents are more satisfied with their current social networks than are younger respondents, who are more likely to say they would like to interact with new partners.

In a longitudinal study, Carstensen (1992) found that interaction frequency and satisfaction with acquaintances declined as participants aged from 18 to 50 years. Moreover, respondents became more focused on a select group of social partners with whom they had increased contact and more satisfying and emotionally close relationships. Interaction frequency with close friends declined, but emotional bonds with them remained in spite of less frequent contact. The changing nature of social relationships which begins at a younger age lends support to socioemotional selectivity theory as a life-span theory.

\section{This Study}

The purpose of this study was to evaluate socioemotional selectivity theory using randomly selected, nationally representative samples interviewed at different historical times. Two cohorts of Americans View Their Mental Health respondents (AVTMH; Gurin, Veroff, \& Feld, 1960; Veroff, Douvan, \& Kulka, 1981), one from 1957 and one from 1976, and one 1980 cohort of respondents from Social Supports of the Elderly (SSE; Antonucci \& Akiyama, 1987; Kahn \& Antonucci, 1984) were analyzed. SSE represents a sample of Americans over age 50 years with oversampling of those over 70 years, whereas AVTMH has respondents as young as 21 years and fewer respondents in the older age categories.

It was hypothesized that data from this study would support socioemotional selectivity theory. Specifically, it was predicted that across cohorts, younger respondents would indicate that they want more friends and people in their social networks than they currently have, whereas more older respondents would be satisfied with the current size of their networks.

At least two positions are possible with regard to expected cohort differences. On the basis of Carstensen's (1993, 1995) theory, cohort differences are not expected because the idea that motivations for different types of social interactions change over the life course does not depend on historical changes that occur over time. Instead, the desire to interact with a select group of intimate social partners rather than with novel social partners results from the anticipation of social endings, which is largely a function of age. This is in contrast to activity theory (Havighurst, 1961; Havighurst \& Albrecht, 1953; Maddox, 1963, 1965) 
which would predict cohort differences based on externally imposed factors that change historically, such as mandatory retirement ages and the availability of resources (such as community centers for older adults). Examining different cohorts is crucial to an understanding of whether developmental phenomena are linked to specific times and places or are more universally applicable.

Although Carstensen's work utilizes an impressive variety of methods and several different samples, socioemotional selectivity theory has not yet been explored using a nationally representative sample of Americans. This study addresses this gap in the literature. In addition, because the samples in this study are large and diverse with respect to many demographic characteristics (such as gender, race, marital status, number of years of education completed, and income), it will be possible to control for, and assess the influence of, these factors on satisfaction with social networks. Researchers have reported that older people without a spouse or children in their social network often compensate for this by closeness with other kin and friends, and thus maintain needed levels of support and companionship by drawing on different sources (Dykstra, 1993; Lang and Carstensen, 1994). On the basis of these results, no differences in network satisfaction by marital status were predicted. Socioemotional selectivity theory makes no claims about expected differences based on gender, race, or socioeconomic status. However, given what is known about gender differences in social relationships, the importance of the extended family for ethnic minorities, and the often pervasive effects of socioeconomic status, it was important to explore these factors in this study. Finally, because Fredrickson and Carstensen (1990) reported effects of infirmity as well as age on preference for particular social partners, it was important to include health status and physical functional impairment in this investigation. In addition to assessing effects of demographic variables and health status, we control for respondents' overall happiness to rule out the possibility that age differences in satisfaction with social networks are merely a function of greater happiness or positivity as people age (e.g., Andrews \& Withey, 1974).

The plan for analysis involves three main steps. First, age differences in satisfaction with current network size are assessed separately for the three samples, and the power of age to predict satisfaction with network size after controlling for demographic variables, overall happiness, and frequency of contact with network members is investigated. On the basis of the above research regarding socioemotional selectivity theory, it was hypothesized that more older respondents than younger respondents would be satisfied with their current network size rather than wanting more friends or a larger network and that age would predict satisfaction above and beyond these control variables. Second, age differences in frequency of contact with network members are investigated. It was hypothesized that older respondents would report less frequent contact with network members than would younger respondents. It appears that overall contact with network members decreases with age, even though contact with select members may remain the same or even increase (Carstensen, 1992). Third, age differences in whether respondents' network size has changed over the last 5 years are explored. It was hypothesized that older respondents would be more likely than younger respondents to report a decrease in network size over the last 5 years because socioemo- tional selectivity theory explicitly predicts that individuals selectively narrow their social networks as they age. Patterns of results were expected to be consistent across cohorts.

\section{Method}

\section{Participants}

Americans View Their Mental Health. National samples of two cohorts were drawn at two historical times by a multistage probability area design which identified increasingly more narrow sampling points at each stage until a single household resident among eligible members was randomly chosen to be interviewed (see Veroff et al., 1981). In $1957,84 \%$ of the randomly selected respondents were successfully interviewed $(N=2,460)$. In $1976,71 \%$ were interviewed $(N=2,264)$. It should be noted that this was a longitudinal repeated cross-sections design (Jackson \& Antonucci, 1994) so the respondents in 1976 were not the same individuals who were interviewed in 1957. Thus, differences in the number of respondents were not the result of attrition but of different sampling outcomes. Participants ranged in age from 21 years to 93 years. Table 1 shows demographic, health, and psychological information about the samples.

Social Supports of the Elderly. Respondents were selected randomly by a three-step process that resulted in a nationally representative sample of individuals aged 50-95 years with oversampling of those over age 70 years (for details see Kahn \& Antonucci, 1984). Interviews were conducted in 1980. The response rate was $70 \%(N=718)$. Key demographic, health, and psychological characteristics of the sample are shown in Table 1.

\section{Measures and Procedure}

Americans View Their Mental Health. Gurin et al. (1960) and Veroff et al. (1981) were responsible for the design of the interview questions and oversaw the two earlier data collections (in 1957 and 1976 respectively). Respondents were interviewed in their homes regarding their well-being and satisfaction, life experience, performance in major roles, psychological stress, and methods of coping with stress. The questions analyzed for this study were identical in the two surveys.

The critical question with respect to addressing socioemotional selectivity theory was posed to respondents as, "Do you feel you have as many friends as you want, or would you like to have more friends?" The possible responses were "I have as many friends as I want" (coded as 1) or "I would like to have more friends" (coded as 0). In 1957, $60 \%$ of respondents had as many friends as they wanted, and $40 \%$ wanted more friends. In 1976, $56 \%$ had as many friends as they wanted, and $44 \%$ wanted more friends.

Frequency of contact with network members was assessed by the question, "About how often do you get together with friends or relatives-I mean things like going out together or visiting in each other's homes?' ' Possible responses ranged from more than once a week (coded as 5) to less than once a month (coded as 1). In 1957, $31 \%$ of respondents had contact with their friends or relatives more than once a week, $34 \%$ once a week, $16 \%$ a few times a month, $10 \%$ once a month, and $9 \%$ less than once a month. In $1976,31 \%$ of respondents had contact with friends or relatives more than once a week, $27 \%$ once a week, $20 \%$ a few times a month, $10 \%$ once a month, and $12 \%$ less than once a month.

In addition to these substantive questions, gender $(1=\operatorname{man}, 2=$ woman), marital status $(0=$ not married, $1=$ married $)$, race $(0=$ African American, $1=$ White $){ }^{1}$ number of years of education com-

\footnotetext{
'Although we recognize that there are many other racial groups with important differences among them, only African Americans and Whites were available for this study because of the very small number of respondents from other racial groups.
} 
Table 1

Demographic, Health, and Psychological Characteristics of Respondents

\begin{tabular}{|c|c|c|c|c|c|c|}
\hline \multirow[b]{3}{*}{ Characteristic } & \multicolumn{4}{|c|}{ AVTMH } & & \\
\hline & \multicolumn{2}{|c|}{$\begin{array}{c}1957 \\
(N=2,460)\end{array}$} & \multicolumn{2}{|c|}{$\begin{array}{c}1976 \\
(N=2,264)\end{array}$} & \multicolumn{2}{|c|}{$\begin{array}{c}\text { SSE } \\
(1980 ; N=718)\end{array}$} \\
\hline & $M$ & $S D$ & $M$ & $S D$ & $M$ & $S D$ \\
\hline Age in years & 42.45 & 14.24 & 42.45 & 15.62 & 66.09 & 10.04 \\
\hline Gender ( $\%$ men) & \multicolumn{2}{|c|}{44} & \multicolumn{2}{|c|}{42} & \multicolumn{2}{|c|}{42} \\
\hline Race (\% White) & \multicolumn{2}{|c|}{92} & \multicolumn{2}{|c|}{89} & \multicolumn{2}{|c|}{91} \\
\hline Marital status (\% married) & \multicolumn{2}{|c|}{$\begin{array}{l}92 \\
76\end{array}$} & \multicolumn{2}{|c|}{64} & \multicolumn{2}{|c|}{58} \\
\hline Education ${ }^{*}$ & 4.08 & 2.27 & 5.13 & 2.19 & 10.53 & 3.75 \\
\hline Income per year (U.S. dollars) & 5,825 & 3,994 & 13,214 & 6,479 & 15,325 & 14,314 \\
\hline Health symptoms & .36 & .48 & 0.40 & .49 & 2.26 & 1.93 \\
\hline Functional limitations & .14 & .35 & .16 & .36 & 1.57 & 1.07 \\
\hline Happiness & 2.26 & .64 & 2.20 & .62 & 2.13 & .64 \\
\hline Frequency of contact & 3.68 & 1.27 & 3.56 & 1.34 & 3.69 & .66 \\
\hline
\end{tabular}

Note. AVTMH $=$ Americans View Their Mental Health; SSE $=$ Social Supports of the Elderly.

"For AVTMH, education is coded as follows: $0=$ no schooling; $1=1-6$ years; $2=7-8$ years; $3=9-$ 11 years; $4=9-11$ years plus other noncollege schooling; $5=$ completed high school (12 years), no other schooling; 6 = completed high school plus other noncollege schooling; $7=$ attended college but has no degree; 8 = college degree. For SSE, education is coded as number of years completed.

pleted $(0=$ no schooling, $1=1-6$ years, $2=7-8$ years, $3=9$ 11 years, $4=9-11$ years with additional noncollege schooling, $5=$ completed high school, $6=$ completed high school with additional noncollege schooling, $7=$ attended college but no degree, $8=$ college degree), annual family income, and two health measures were examined as demographic control variables because of the possibility that these would influence satisfaction with social networks. One health measure was a question asking whether the respondent had any particular health trouble $(0=$ no, $1=$ yes $)$. The other health measure addressed the issue of functional impairment by asking respondents whether they were healthy enough to carry out the things they wanted to do $(0=y e s, 1$ $=$ no). Finally, the question, "Taking things all together, how would you say things are these days - would you say you're very happy, pretty happy, or not too happy these days?' (coded as 3,2, and 1 respectively) was used to address the concern that perhaps older adults report greater satisfaction with social networks because of general positivity with age. See Table 1 for descriptive information regarding these measures.

Social Supports of the Elderly. Kahn and Antonucci were the principal investigators involved in the collection of these data in 1980 (Antonucci \& Akiyama, 1987; Kahn \& Antonucci, 1984). Respondents were interviewed in their homes, and all respondents were asked the same questions. The questions focused primarily on social support.

The focus of the present study was on responses to the question, "About changing your [social] network, would you want to have more people in it?" Respondents answered either "yes" (coded as 0 ) or "no" (coded as 1). More respondents were satisfied with the size of their social networks $(68 \%)$ than not satisfied $(32 \%)$. Frequency of contact with network members, which ranged from daily (coded as 5) to never (coded as 1), also was examined. Twelve percent of respondents had daily contact with their network members, $53 \%$ once a week, $31 \%$ once a month, $2 \%$ once a year, and $1 \%$ never. Responses to the question, "Compared to five years ago, has the number of people in your network increased, decreased, or remained about the same?" (increased coded as 1 , remained the same as 0 , and decreased as -1 ) were of interest. Overall, $19 \%$ of respondents said their network size had decreased over the last 5 years, $14 \%$ said it had increased, and $66 \%$ said it had remained the same.

As with AVTMH, gender $(1=\operatorname{man}, 2=$ woman $)$, marital status $(0$ $=$ not married, $1=$ married $)$, race $(0=$ African American, $1=$ White $)$, number of years of education completed, annual family income, and two health measures were used as demographic control variables. One measure of health was a checklist including 14 possible health problems such as ulcers, hypertension, and cancer. The other was a question regarding the respondent's need for functional care (i.e., whether it was needed never, once in a while, sometimes, or often coded 1, 2, 3, or 4 respectively). Finally, a question identical to the question asking about overall happiness in AVTMH was asked of SSE respondents, "Taking things all together, how would you say things are these days - would you say you're very happy, pretty happy, or not too happy these days?' (coded as 3,2 , and 1 respectively). It should be noted that these control variables were carefully selected to be as comparable as possible between AVTMH and SSE. See Table 1 for descriptive information regarding these variables.

\section{Analysis Plan}

The plan for analysis was as follows. One-way analysis of variance (ANOVA) was used to examine age differences in satisfaction with current number of friends and satisfaction with network size for AVTMH and SSE respectively as well as frequency of contact with network members for all cohorts and change in network size over the last 5 years for SSE. It should be noted that although ANOVA techniques with a dichotomous dependent variable can violate assumptions that lead to problems with Type 1 errors and the power of the test, we justify the use of this approach on the basis of criteria set forth by Hsu and Feldt (1969) and Lunney (1970), specifically that ANOVA is an appropriate statistical technique for analyzing dichotomous data if the proportion of responses in the smaller response category is at least 20 and there are at least 20 degrees of freedom for error. Our data satisfy these requirements. A regression-based strategy was adopted next to allow prediction of satisfaction with network size after controlling for key demographic variables, overall happiness, and frequency of contact with network members. Logistic regression was conducted because this technique permits use of dichotomous dependent variables. For AVTMH, analyses were conducted separately by cohort with one exception to test for cohort differences in satisfaction with current number of friends and frequency of contact with network members. Where appropriate, effect size information as described by Cohen (1988) is presented following significance tests. 


\section{Results}

Age Differences in Satisfaction With Current Number of Friends and Desire for a Larger Social Network

Americans View Their Mental Health. Five age categories (i.e., 21-29, 30-39, 40-49, 50-59, and 60+ years) were used for this set of analyses. Analyses were conducted separately by cohort.

For the 1957 cohort, a one-way ANOVA of satisfaction with current number of friends by age showed significant differences in satisfaction depending on the age of the respondent, $F(4$, 2424) $=4.26, p<.01$, Cohen's $d=.23$. Post hoc Bonferroni tests showed that significantly more respondents in the oldest group than the youngest three groups were satisfied with their current number of friends (see Table 2).

For the 1976 cohort, a one-way ANOVA of satisfaction with current number of friends by age also showed significant differences in satisfaction depending on the age of the respondent, $F(4,2234)=7.43, p<.001$, Cohen's $d=.32$. Post hoc Bonferroni tests revealed that significantly fewer members of the youngest group than all four older groups were satisfied with their current number of friends. Although more adults in the second oldest group than in the oldest group were satisfied with their current number of friends, means for the two oldest groups showed no significant difference (see Table 2).

Social Supports of the Elderly. The SSE sample, which included people 50 years of age and older, was divided into three age categories (i.e., 50-59, 60-69, and 70+ years) for the following analyses. A one-way ANOVA of satisfaction by age showed a significant difference, $F(2,696)=5.23, p<.01$, Cohen's $d=.25$. Post hoc Bonferroni tests indicated that the oldest group was significantly less likely to want more people in their network than were the younger two groups (see Table 2).

\section{Age Differences in Frequency of Contact With Network Members}

Americans View Their Mental Health. One-way ANOVAs were conducted to investigate whether older respondents had less frequent contact than younger respondents with their network members. For 1957, there were significant age differences in frequency of contact with network members, $F(4,2435)=$ 21.80, $p<.001$, Cohen's $d=.54$. Post hoc Bonferroni tests revealed that the youngest group had more frequent contact with friends and relatives than all other age groups. The oldest and middle age groups also had less frequent contact than the second youngest age group. For 1976, there also were significant age differences in frequency of contact with network members, $F$ $(4,2246)=18.13, p<.001$, Cohen's $d=.46$. Post hoc Bonferroni tests showed that the youngest group had more frequent contact with network members than all other age groups (see Table 2).

Social Supports of the Elderly. A one-way ANOVA of the mean frequency of contact with social network members by age showed significant differences in the frequency of contact by age, $F(2,674)=6.82, p<.01$, Cohen's $d=.30$. Post hoc Bonferroni tests showed that the youngest group had signifi-

Table 2

Means and Standard Deviations of Current Satisfaction, Frequency of Contact, and Change in Network Size by Age in Years

\begin{tabular}{|c|c|c|c|c|c|c|c|}
\hline \multirow{2}{*}{$\begin{array}{c}\text { Cohort/age range } \\
\text { (years) }\end{array}$} & \multirow[b]{2}{*}{$N$} & \multicolumn{2}{|c|}{$\begin{array}{c}\text { Current } \\
\text { satisfaction }\end{array}$} & \multicolumn{2}{|c|}{$\begin{array}{c}\text { Frequency of } \\
\text { contact }\end{array}$} & \multicolumn{2}{|c|}{$\begin{array}{l}\text { Change } \\
\text { in size }\end{array}$} \\
\hline & & $M$ & $S D$ & $M$ & $S D$ & $M$ & $S D$ \\
\hline \multicolumn{8}{|l|}{ AVTMH 1957} \\
\hline $21-29$ & 456 & $0.55_{\mathrm{a}}^{\mathrm{c}}$ & 0.50 & $4.11_{\mathrm{a}}^{\mathrm{c}}$ & 1.04 & & \\
\hline $30-39$ & 586 & $0.58^{\mathrm{c}}$ & 0.50 & $3.74_{\mathrm{a}}^{\mathrm{d}, e}$ & 1.18 & & \\
\hline $40-49$ & 517 & $0.58^{c}$ & 0.49 & $3.52^{\mathrm{d}, \mathrm{f}}$ & 1.29 & & \\
\hline $50-59$ & 393 & 0.63 & 0.48 & $3.62_{\mathrm{a}}^{\mathrm{d}}$ & 1.27 & & \\
\hline $60+$ & 508 & $0.67_{\mathrm{a}}^{\mathrm{d}}$ & 0.47 & $3.42^{\mathrm{d}, \mathrm{f}}$ & 1.42 & & \\
\hline All ages & $\cdot 2,460$ & 0.60 & 0.49 & 3.68 & 1.27 & & \\
\hline \multicolumn{8}{|l|}{ AVTMH 1976} \\
\hline $21-29$ & 553 & $0.47_{\mathrm{b}}^{\mathrm{c}}$ & 0.50 & $3.96_{\mathrm{b}}^{\mathrm{c}}$ & 1.21 & & \\
\hline $30-39$ & 463 & $0.57^{\mathrm{d}}$ & 0.50 & $3.49_{\mathrm{b}}^{\mathrm{d}}$ & 1.31 & & \\
\hline $40-49$ & 342 & $0.57^{\mathrm{d}}$ & 0.50 & $3.48^{\mathrm{d}}$ & 1.27 & & \\
\hline $50-59$ & 343 & $0.63^{\mathrm{d}}$ & 0.48 & $3.36_{\mathrm{h}}^{\mathrm{d}}$ & 1.35 & & \\
\hline $60+$ & 563 & $0.60_{b}^{d}$ & 0.49 & $3.38^{d}$ & 1.43 & & \\
\hline All ages & 2,264 & 0.56 & 0.50 & 3.56 & 1.34 & & \\
\hline \multicolumn{8}{|l|}{ SSE 1980} \\
\hline $50-59$ & 233 & $0.63^{c}$ & 0.48 & $3.83^{c}$ & 0.62 & -0.04 & 0.60 \\
\hline $60-69$ & 206 & $0.64^{c}$ & 0.48 & $3.63^{d}$ & 0.70 & -0.03 & 0.57 \\
\hline $70+$ & 279 & $0.75^{\mathrm{d}}$ & 0.43 & $3.63^{d}$ & 0.66 & -0.05 & 0.56 \\
\hline All ages & 718 & 0.68 & 0.47 & 3.69 & 0.66 & -0.04 & 0.57 \\
\hline
\end{tabular}

Note. Within AVTMH age groups, subscripts of $\mathrm{a}$ and $\mathrm{b}$ identify significantly different means between 1957 and 1976. Within each cohort, superscripts of $c$ and d identify significantly different means between age groups, as do superscripts of e and f. AVTMH = Americans View Their Mental Health; SSE = Social Supports of the Elderly. 
cantly more contact with their network members than did the two older groups (see Table 2).

\section{Age Differences in Change in Network Size Over the Last 5 Years}

This information was available only in Social Supports of the Elderly. A one-way ANOVA showed no significant age differences in change in network size over the last 5 years.

\section{Cohort Differences in Satisfaction With Current Number of Friends and Frequency of Contact With Network Members}

Participants in the 1976 wave of AVTMH were asked identical questions to those asked in 1957 regarding satisfaction with current number of friends and frequency of contact with network members, making possible a test for cohort differences in these variables. The $t$ tests indicated that overall, compared to respondents in 1976, respondents in 1957 were more satisfied with their current number of friends, $t(4680)=2.66, p<.01$, Cohen's $d$ $=.08$, and had more frequent contact with network members, $t(4703)=3.17, p<.01$, Cohen's $d=.09$. As shown in Table 2 , some differences were found for certain age groups as well. With regard to satisfaction with current number of friends, differences were found between the youngest groups, $t(996)=$ $2.72, p<.01$, Cohen's $d=.17$, and the oldest groups, $t(1049)$ $=2.16, p<.05$, Cohen's $d=.13$ in 1957 and 1976 with respondents in 1957 being more satisfied. With regard to frequency of contact with network members, differences were found between the youngest groups, $t(1001)=2.06, p<.05$, Cohen's $d=.13$; second youngest groups, $t(1043)=3.32, p$ $<.01$, Cohen's $d=.21$; and second oldest groups, $t(726)=$ $2.64, p<.01$, Cohen's $d=.20$, with respondents in each 1957 age group having more frequent contact with network members than corresponding age groups in 1976. It should be noted that although these cohort differences are statistically significant, the effect sizes are small by Cohen's (1988) standards.

Cohort differences between AVTMH and SSE were not tested because different questions and scales were used to assess satisfaction with current social network and frequency of contact with network members in these two surveys, making direct comparison of differences questionable conceptually as well as methodologically.

\section{Prediction of Satisfaction With Current Number of Friends and Desire for a Larger Social Network Controlling for Demographic, Health, Psychological and Network Characteristics}

Using logistic regression analyses, the extent to which age would predict satisfaction with current number of friends after controlling for several relevant demographic, health, psychological, and network characteristics was investigated. Control variables included gender, race, marital status, number of years of education completed, income, health symptoms, functional physical impairment, overall happiness, and frequency of contact with network members. These nine variables were entered on the first step of the regression, and age was entered on the second step. A chi-square test at the first step reveals the significance of the entire model. At the second step, the chisquare tests the model containing age against the model containing only the aforementioned control variables. A $p$ value associated with the Wald statistic indicates the significance of each individual predictor at both steps. Effects of interactions between predictors were explored, specifically to test whether satisfaction with current number of friends and social networks was differentially related to age depending on respondents' marital status. These interaction terms did not contribute significantly to the prediction of satisfaction. The results reported below are, therefore, of simpler analyses that do not include interaction terms.

Americans View Their Mental Health. In 1957, the set of demographic variables alone significantly predicted satisfaction with current number of friends, $\chi^{2}(10, N=2,460)=25.14, p$ $<.01$. Age was a significant predictor of satisfaction above and beyond the other predictors, $\chi^{2}(1, N=2,460)=10.60, p<$ .01. Parameter estimates and odds ratios are shown in Table 3 . Of particular interest is the result that individuals' likelihood of being satisfied with their current number of friends increased by a factor of 1.12 for every unit increase in age (which in this case is about a decade). At each step, $59 \%$ of respondents were correctly classified by the model according to whether they were satisfied with their current number of friends. It should be noted that an alternative model including age as the only predictor of satisfaction with current number of friends was also significant, $\chi^{2}(2, N=2,460)=15.58, p<.001$, and correctly classified $60 \%$ of respondents. Menard (1995) describes problems of using classification tables in logistic regression that will be discussed below.

In 1976, the control variables alone did not predict satisfaction with current number of friends, $\chi^{2}(10, N=2,264)=$ $12.99, n s$. The model with age added, however, was significant, $\chi^{2}(1, N=2,264)=19.65, p<.001$. As shown in Table 3, with each decade, the likelihood of respondents' being satisfied with their current number of friends increased by a factor of 1.17. Fifty-six percent and $57 \%$ of respondents were correctly classified at the first and second steps respectively. An alternative model including age as the only predictor was significant, $\chi^{2}(2$, $N=2,264)=21.47, p<.001$, and correctly classified $58 \%$ of respondents.

Social Supports of the Elderly. The set of control variables entered at the first step did not predict desire for a larger social network, $\chi^{2}(10, N=718)=8.20, n s$. Adding age to the model, however, resulted in significant prediction of the desire for a larger network size, $\chi^{2}(1, N=718)=11.13, p<.001$. Parameter estimates and odds ratios for each predictor are shown in Table 3. As evident, a unit increase in age (again, about a decade), resulted in an increased likelihood of respondents' being satisfied with their current network size by a factor of 1.51. Sixty-seven percent and $68 \%$ of respondents were correctly classified at the first and second steps respectively. An alternative model with age as the only predictor was significant, $\chi^{2}(2, N$ $=718)=8.80, p<.01$, and resulted in the correct classification of $68 \%$ of respondents.

\section{Discussion}

This study represents a unique examination of socioemotional selectivity theory across cohorts spanning the years 1957-1980 
Table 3

Predictors of Satisfaction With Network Size

\begin{tabular}{|c|c|c|c|c|c|c|c|c|c|}
\hline \multirow[b]{2}{*}{ Variable } & \multicolumn{3}{|c|}{$\begin{array}{c}\text { AVTMH } 1957 \\
(N=2,460)\end{array}$} & \multicolumn{3}{|c|}{$\begin{array}{l}\text { AVTMH } 1976 \\
(N=2,264)\end{array}$} & \multicolumn{3}{|c|}{$\begin{array}{l}\text { SSE 1980 } \\
(N=718)\end{array}$} \\
\hline & $B$ & $S E B$ & $\begin{array}{l}\text { Odds } \\
\text { ratio }\end{array}$ & $B$ & $S E B$ & $\begin{array}{l}\text { Odds } \\
\text { ratio }\end{array}$ & $B$ & $S E B$ & $\begin{array}{l}\text { Odds } \\
\text { ratio }\end{array}$ \\
\hline \multicolumn{10}{|l|}{ Step 1} \\
\hline Gender ${ }^{2}$ & -0.13 & 0.09 & 0.87 & -0.07 & 0.09 & 0.94 & -0.16 & 0.20 & 0.85 \\
\hline Race $^{\mathrm{b}}$ & 0.44 & $0.16^{* *}$ & 1.55 & -0.10 & 0.15 & 0.90 & 0.10 & 0.32 & 1.10 \\
\hline Marital status ${ }^{c}$ & -0.17 & 0.11 & 0.84 & -0.15 & 0.11 & 0.86 & -0.02 & 0.21 & 0.98 \\
\hline Education & -0.07 & $0.02 * *$ & 0.93 & -0.04 & 0.02 & 0.96 & -0.03 & 0.03 & 0.97 \\
\hline Income & 0.02 & 0.01 & 1.02 & 0.01 & 0.01 & 1.01 & 0.00 & 0.01 & 1.00 \\
\hline Health symptoms & -0.13 & 0.10 & 0.87 & 0.06 & 0.10 & 1.06 & -0.05 & 0.05 & 0.95 \\
\hline Functional limitations & -0.02 & 0.14 & 0.98 & -0.14 & 0.15 & 0.87 & 0.02 & 0.10 & 1.02 \\
\hline Frequency of contact & -0.05 & 0.04 & 0.95 & -0.04 & 0.03 & 0.96 & 0.26 & 0.15 & 1.29 \\
\hline Overall happiness & 0.06 & 0.07 & 1.06 & 0.21 & $0.08 * *$ & 1.24 & 0.13 & 0.14 & 1.13 \\
\hline Constant & 0.58 & $0.29 *$ & & 0.26 & 0.3 & & 0.13 & 0.88 & \\
\hline Model chi-squared & & $25.14^{* *}$ & & & 12.99 & & & 8.20 & \\
\hline Degrees of freedom & & 10 & & & 10 & & & 10 & \\
\hline \multicolumn{10}{|l|}{ Step 2} \\
\hline Gender & -0.11 & 0.09 & 0.90 & -0.06 & 0.09 & 0.95 & -0.16 & 0.21 & 0.86 \\
\hline Race & 0.38 & $0.16^{*}$ & 1.47 & -0.17 & 0.15 & 0.85 & -0.10 & 0.33 & 0.91 \\
\hline Marital status & -0.08 & 0.11 & 0.92 & -0.13 & 0.11 & 0.88 & 0.04 & 0.21 & 1.04 \\
\hline Education & -0.05 & $0.02 *$ & 0.95 & -0.01 & 0.03 & 0.99 & -0.03 & 0.03 & 0.97 \\
\hline Income & 0.02 & 0.01 & 1.02 & 0.01 & 0.01 & 1.01 & 0.01 & 0.01 & 1.01 \\
\hline Health symptoms & -0.18 & 0.10 & 0.83 & -0.04 & 0.10 & 0.96 & -0.07 & 0.05 & 0.93 \\
\hline Functional limitations & -0.06 & 0.14 & 0.94 & -0.21 & 0.15 & 0.81 & -0.04 & 0.10 & 0.96 \\
\hline Frequency of contact & -0.04 & 0.04 & 0.96 & -0.02 & 0.04 & 0.98 & 0.32 & $0.15^{*}$ & 1.37 \\
\hline Overall happiness & 0.06 & 0.07 & 1.06 & 0.20 & $0.08 *$ & 1.22 & 0.07 & 0.15 & 1.07 \\
\hline Age & 0.12 & $0.04 * *$ & 1.12 & 0.15 & $0.03 * * *$ & 1.17 & 0.41 & $0.12 * *$ & 1.51 \\
\hline Constant & 0.09 & 0.33 & & -0.33 & 0.33 & & -0.64 & 0.92 & \\
\hline Model chi-squared & & $10.60^{* *}$ & & & $19.65 * * *$ & & & $11.13 * * *$ & \\
\hline Degrees of freedom & & 1 & & & 1 & & & 1 & \\
\hline
\end{tabular}

Note. Parameter estimates were obtained from logistic regression equations. AVTMH $=$ Americans View Their Mental Health; SSE $=$ Social Supports of the Elderly.

${ }^{\mathrm{a}}$ Men $=1$; women $=2 . \quad{ }^{\mathrm{b}}$ African American $=0$; White $=1 . \quad{ }^{\text {"Not }}$ married $=0$; married $=1$.

$* p<.05 . * * p<.01 . * * * p<.001$.

and ages ranging from 21 to 95 years. Results generally support ideas about social interactions across the life span as outlined by Carstensen $(1993,1995)$ in socioemotional selectivity theory. A major contribution of this study is that it included responses of nationally representative samples from three different cohorts. More older adults than younger adults in both cohorts of the Americans View Their Mental Health survey and the Social Supports of the Elderly survey were satisfied with their current number of friends and size of their social networks, supporting our first hypothesis. Our hypothesis that older adults would have less frequent contact with network members than would younger adults was also generally supported.

Despite this general consistency with socioemotional selectivity theory, some of our results were not as would be predicted by the theory. Specifically, in the AVTMH 1976 sample, fewer respondents in the youngest age group were satisfied with their current number of friends than were respondents in all four older groups. However, the older groups did not differ significantly from one another. Furthermore, also in AVTMH 1976, the youngest group had more frequent contact with their network members than did the four older age groups, but again, the older age groups did not differ from one another. These effects are in the direction predicted by socioemotional selectivity theory, but the theory would predict differences among older age groups as well, with more individuals in each age group expected to be satisfied than in each younger age group. It appears that the youngest age group in the AVTMH 1976 sample was distinctive and responsible for age differences that emerged for this sample. Results from AVTMH 1957 and SSE 1980 were more consistent with predictions based on socioemotional selectivity theory that age differences would emerge with regard to all age groups, not just the youngest in comparison to the others. It should also be noted that although groups older than the youngest in AVTMH 1976 were not significantly different from one another, a comparison of group means indicates that they are generally in the expected direction.

Our third hypothesis, that more older adults than younger adults would report a decrease in social network size over the last 5 years was not supported. It was only possible to test this hypothesis in the SSE sample, and no age differences were found with regard to change in network size. This finding is surprising in light of predictions based on socioemotional selectivity theory that individuals selectively narrow their social networks as they age. It is possible that 5 years is too restricted a time frame to study this change, and Carstensen (1993, 1995) does advance this theory as a life-span account of social relationships. If social networks are indeed becoming progressively more selected throughout the adult years, individuals may not notice these gradual changes within a 5 -year period. 
Carstensen (1993, 1995) explains changes in social contact with age in terms of goals for interpersonal interactions that change over time and with respect to one's anticipation of social endings. According to the theory, the increased salience of death during older age leads to the desire to limit social interactions to close network members rather than spending limited time on forming new relationships or interacting with mere acquaintances. Although we did not test respondents' anticipation of social endings, we predicted that on the basis of Carstensen's work in this domain (e.g., Fredrickson \& Carstensen, 1990), the relation between age and satisfaction with the current social networks would not depend on demographic variables such as gender, race, marital status, number of years of education completed, and income. This expectation was confirmed. It should be noted that because we controlled for demographic, health, and psychological variables as well as frequency of contact with network members in the logistic regression analyses, age can be said to predict satisfaction with current networks above and beyond other potential explanatory factors. On the basis of the claims of socioemotional selectivity theory that anticipated endings increase the desire to maintain contact with only a select group of network members, one may expect that health status would influence satisfaction with network size. This was not the case. However, these samples were all community-dwelling and thus relatively well-functioning. It should be noted that nursing home residents differ from older adults living in the community (Fredrickson \& Carstensen, 1990). The central finding in this study was that age, not other demographic factors, consistently predicted satisfaction with current network size.

Adding age to the logistic regression models did not lead to correct classification of a higher proportion of respondents with respect to their satisfaction with current social networks. Menard (1995) discusses the problem of using classification tables in logistic regression analyses in terms of the distinction between the strength of a relation between an independent and dependent variable versus the strength of the relation between predicted group membership and observed group membership. Consistent with Menard's (1995) argument, in these analyses, knowing age led to better prediction of satisfaction with social networks without changing the percent of respondents correctly categorized.

Older respondents reported less frequent contact with their network members suggesting that perhaps older respondents were being more selective about contact they had with network members in addition to the number of people they wanted in the network. However, frequency of contact was not an important predictor of satisfaction with network size. Furthermore, overall happiness was not a significant predictor of satisfaction with network size which suggests that current satisfaction with network size is not simply a function of overall satisfaction with life.

Effect sizes in this study ranged from .08 (for cohort differences in satisfaction with current number of friends) to .54 (for age differences in frequency of contact with network members). These effects are small to medium in magnitude by Cohen's (1988) guidelines. Effects of this magnitude are not uncommon in non-experimental work (Cohen, 1988), but they should be recalled when considering these results.

This study has limitations. First, each respondent was interviewed at only one point in time so the age comparisons reported are cross-sectional rather than following the same individuals over time. According to socioemotional selectivity theory there should be intraindividual change over time as individuals selectively narrow their networks, but it is not possible to test this idea using cross-sectional data. Because different cohorts were investigated, however, the possibility that age differences in satisfaction with current social networks were due solely to historical influences affecting a particular cohort is reduced. Extending socioemotional selectivity theory over three cohorts spanning four decades is an important contribution of this study. Results were consistent with socioemotional selectivity theory across all cohorts.

A second limitation is that the analyses reported above compared only White and African American respondents because there were so few respondents of other races $(.5 \%$ and $2.7 \%$ in 1957 and 1976 respectively for AVTMH, and $1.4 \%$ for SSE). The percentage of African American respondents was comparable to the percentage in the United States estimated by the Current Population Survey (see Veroff et al., 1981 for details), but the number of African American respondents was still small compared to the number of White respondents. Thus, these results should be interpreted with caution. It should be noted, though, that socioemotional selectivity theory makes no predictions regarding race. Nevertheless, future studies that oversample for racial and ethnic minorities would be useful for testing for possible differences according to these demographic characteristics.

A third limitation involves difficulty in interpreting findings regarding frequency of contact with network members without knowing the absolute size and composition of social networks for each age group. One might expect frequency of contact with network members to decrease with age (Antonucci, 1990; Chappell, 1992), particularly if older adults' networks are smaller than the networks of younger adults. However, it is possible that frequency of contact with network members remains stable across age groups as older adults interact less frequently with acquaintances but more frequently with close friends and relatives. We found that younger respondents had more frequent contact with network members than did older respondents, but we cannot say whether this difference in contact was a result of younger respondents' spending more time with acquaintances or having generally larger networks.

This study has broad implications for thinking about social relationships across the life course. In contrast to activity theory (Havighurst, 1961; Havighurst \& Albrecht, 1953; Maddox, $1963,1965)$, which posits that older people desire social contact but are impeded from it by external forces, older respondents in this study were actually more satisfied with the size of their social networks and current number of friends than were younger respondents, a pattern that was consistent across cohorts. This suggests that interventions designed to increase older adults' social contacts with new partners may be misguided. In contrast to disengagement theory (Cumming \& Henry, 1961), which holds that decreased social contact occurs as older adults and society mutually withdraw from one another in a symbolic preparation for death, this study provides evidence that individuals in their thirties are already less likely than those in their twenties to indicate that they would like to have more friends, suggesting that changes in desire for particular social relationships occur over the entire life course, not just during older age. 
In conclusion, Carstensen's (1993, 1995) socioemotional selectivity theory was supported using three nationally representative samples interviewed at different historical times. Older respondents across cohorts were indeed more satisfied than younger respondents with their current social networks.

\section{References}

Andrews, F., \& Withey, S. (1974). Developing measures of perceived life quality: Results from several national surveys. Social Indicators Research, 1, 1-26.

Antonucci, T. C. (1990). Social supports and social relationships. In R. H. Binstock \& L. K. George (Eds.), Handbook of aging and the social sciences (pp. 205-226). San Diego, CA: Academic Press.

Antonucci, T. C., \& Akiyama, H. (1987). Social networks in adult life and a preliminary examination of the convoy model. Journal of Gerontology, 42, 519-527.

Antonucci, T. C., \& Jackson, J. S. (1987). Social support, interpersonal efficacy, and health. In L. L. Carstensen \& B. A. Edelstein (Eds.), Handboak of clinical gerontology (pp. 291-311). New York: Pergamon Press.

Blazer, D. (1982). Social support and mortality in an elderly community population. American Journal of Epidemiology, 115, 684-694.

Carstensen, L. L. (1986). Social support among the elderly: Limitations of behavioral interventions. Behavior Therapist, 6, 111-113.

Carstensen, L. L. (1992). Social and emotional patterns in adulthood: Support for socioemotional selectivity theory. Psychology and Aging, 7, 331-338.

Carstensen, L. L. (1993). Motivation for social contact across the life span: A theory of socioemotional selectivity. In J. E. Jacobs (Ed.), Nebraska Symposium on Motivation: Vol. 40. Developmental perspectives on motivation-Current theory and research in motivation (pp. 209-254). Lincoln: University of Nebraska Press.

Carstensen, L. L. (1995). Evidence for a life-span theory of socioemotional selectivity. Current Directions in Psychological Science, 4 , $151-156$.

Carstensen, L. L., \& Erickson, R. E. (1986). Enhancing the social environments of elderly nursing home residents: Are high rates of interaction enough? Journal of Applied Behavior Analysis, 19, 349-355.

Carstensen, L. L., Gottman, J. M., \& Levenson, R. W. (1995). Emotional behavior in long-term marriage. Psychology and Aging, 10, 140-149.

Carstensen, L. L., Gross, J. J., \& Fung, H. H. (1998). The social context of emotional experience. In K. W. Schaie \& M. P. Lawton (Vol. Eds.), Annual review of gerontology and geriatrics: Vol. 17. Focus on emotion and adult development (pp. 325-352). New York: Springer.

Chappell, N. L. (1992). Social support and aging. Toronto, Ontario, Canada: Butterworths.
Cohen, J. (1988). Statistical power analysis for the behavioral sciences (2nd ed.). Hillsdale, NJ: Erlbaum.

Cumming, E., \& Henry, W. E. (1961). Growing old: The process of disengagement. New York: Basic Books.

Dykstra, P. (1993). The differential availability of relationships and the provision and effectiveness of support to older adults. Journal of Social and Personal Relationships, 10, 355-370.

Fredrickson, B. L., \& Carstensen, L. L. (1990). Choosing social partners: How old age and anticipated endings make people more selective. Psychology and Aging, 5, 335-347.

Gurin, G., Veroff, J., \& Feld, S. (1960). Americans view their mental health. New York: Basic Books.

Havighurst, R. J. (1961). Successful aging. Gerontologist, 1, 8-13.

Havighurst, R. J., \& Albrecht, R. (1953). Older people. New York: Longmans.

Herzog, A. R., \& Rodgers, W. L. (1981). Age and satisfaction: Data from several large surveys. Research on Aging, 3, 142-165.

Hsu, T., \& Feldt, L. S. (1969). The effect of limitations on the number of criterion score values on the significance level of the $F$-test. American Educational Research Journal, 6, 515-527.

Jackson, J. S., \& Antonucci, T. C. (1994). Survey methodology in lifespan human development research. In S. Cohen \& H. Reese (Eds.), The West Virginia University conferences on life-span developmental psychology: Vol. 13. Life-span developmental psychology-Methodological contributions (pp. 65-94). Hillsdale, NJ: Erlbaum.

Kahn, R. L., \& Antonucci, T. C. (1984). Supports of the elderly: Family/ friends/ professionals-Final report. Washington, DC: National Institute on Aging.

Lang, F. R., \& Carstensen, L. L. (1994). Close emotional relationships in late life: Further support for proactive aging in the social domain. Psychology and Aging, 9, 315-324.

Larson, R. (1978). Thirty years of research on the subjective well-being of older Americans. Journal of Gerontology, 33, 109-125.

Lunney, G. H. (1970). Using analysis of variance with a dichotomous dependent variable: An empirical study. Journal of Educational Measurement, 7, 263-269.

Maddox, G. L. (1963). Activity and morale: A longitudinal study of selected elderly subjects. Social Forces, 42, 195-204.

Maddox, G. L. (1965). Fact and artifact: Evidence bearing on disengagement theory from the Duke Geriatrics Project. Human Development, 8, 117-130.

Menard, S. (1995). Applied logistic regression analysis. Thousand Oaks, CA: Sage.

Veroff, J., Douvan, E., \& Kulka, R. A. (1981). The inner American: A self-portrait from 1957 to 1976. New York: Basic Books.

Received June 10, 1997

Revision received March 18, 1998 Accepted March 18, 1998 